\title{
Karakteristik UDT (Undescended Testis) di RSAB Harapan Kita tahun 2009
}

Aditya Suryansyah

RS Anak dan Bunda Harapan Kita, Jakarta

Latar belakang. Undescended testis (UDT) merupakan testis yang tidak turun pada tempatnya. Sehingga apabila testis belum turun pada usia dua tahun akan menurunkan fertilitas.

Tujuan. Mengetahui karakteristik pasien UDT yang datang ke RSAB Harapan Kita.

Metode. Penelitian UDT di RSAB Harapan Kita, antara Januari-Desember 2009, dan dilakukan secara retrospektif.

Hasil. Didapatkan 78 pasien yang memenuhi kriteria inklusi. Tigapuluh tiga pasien (42\%) datang tanpa rujukan, 28 di antaranya berusia lebih dari 2 tahun. Menurut tempatnya, UDT bilateral $21,8 \%$ dan sisanya unilateral. Pasien yang diberikan terapi hormon (hCG) 48 pasien, dengan angka keberhasilan 50\%, angka keberhasilan lebih tinggi (55\%) bila dilakukan pada usia 6 bulan-1 tahun. Pasien yang dioperasi (orchidopexy) 34 pasien, 41,2\% pasien dioperasi setelah terapi hormon gagal. Pasien yang menjalani orchidopexy pada usia 2-5 tahun dan usia di atas 5 tahun berturut-turut 47,1\% dan 29,4\%.

Kesimpulan. Disimpulkan bahwa masih banyak kasus UDT yang terlambat didiagnosis. Keterlambatan ini akan mempengaruhi keberhasilan terapi. Sari Pediatri 2011;13(1):1-4.

Kata kunci: UDT, hCG, orchidopexy, usia

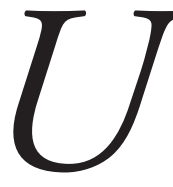

ndescended testis (UDT) atau cryptorchidism merupakan kelainan pada testis anak karena terhentinya proses penurunan salah satu atau kedua testis di dalam jalurnya antara rongga abdomen dengan skrotum. Kejadian UDT merupakan kelainan genitalia kongenital tersering pada anak laki-laki. ${ }^{1,2}$ Angka kejadiannya $4 \%-5 \%$ pada bayi laki-laki yang lahir cukup bulan dan meningkat menjadi

\footnotetext{
Alamat korespondensi:

Dr. Aditya Suryansyah, Sp.A. Staf Bagian Endokrinologi Anak RS Anak dan Bunda Harapan Kita Jakarta, Jl. Letjen S. Parman Kav. 87, Slipi. Telp.021-5684085-93. E-mail: adityasuryansyah@yahoo.com
}

9\%-30\% pada bayi prematur. ${ }^{1,2}$ Dilaporkan 21\% kasus UDT terjadi pada bayi berat badan lahir kurang dari 2500 gram. ${ }^{3}$ Dengan bertambahnya usia, testis mengalami desensus secara spontan sekitar 70\%-77\%, pada umumnya terjadi pada usia 3 bulan. ${ }^{1,2,4,5}$ Pada usia 6 bulan kejadiannya desensus menjadi 0,8\%.,6

Undescended testis merupakan kelainan kongenital yang terjadi sejak lahir, namun terdapat peningkatan jumlah kasus pada usia lebih tua yang didiagnosis UDT. ${ }^{1,3}$ Hal tersebut dikarenakan banyak pasien datang terlambat untuk melakukan pemeriksaan ke dokter ahli endokrinologi anak atau dokter bedah, serta pemeriksaan testis saat lahir dan pada usia kurang dari satu tahun tidak dilakukan. 
Tata laksana UDT yang terlambat akan menimbulkan dampak pada testis di kemudian hari. Kejadian UDT meningkatkan risiko infertilitas dan berhubungan dengan risiko tumor sel germinal meningkat 2-8 kali. Setelah usia dua tahun sebanyak seperlima bagian dari sel-sel germinal testis telah mengalami kerusakan, ${ }^{8}$ oleh sebab itu UDT perlu diturunkan sebelum usia 2 tahun. Pengobatan UDT dapat berupa terapi hormonal, pembedahan, atau kombinasi keduanya. ${ }^{1,4,5,6}$ Terapi dengan human chorionic gonadrotropin hormone ( $h C G$ ) dilaporkan sukses pada 10\%-50\% kasus. Pembedahan dilakukan jika gagal pada terapi hormonal, atau usia sudah di atas dua tahun. ${ }^{?}$

Pasien UDT banyak yang datang ke RSAB Harapan Kita, namun belum ada data karakteristik pasien yang meliputi jumlah pasien, usia saat datang, dan alasan keterlambatan terapi, sehingga perlu adanya penelitian.

\section{Metode}

Penelitian retrospektif deskriptif terhadap anak yang berobat jalan di Poliklinik Endokrinologi Anak dan Poliklinik Bedah di Rumah Sakit Anak dan Bunda (RSAB) Harapan Kita, pada JanuariDesember 2009. Semua anak yang mengalami UDT berdasarkan pemeriksaan fisik diikutkan dalam penelitian ini. Diagnosis berdasarkan gambaran klinis UDT. Data yang dilaporkan meliputi anamnesis berdasarkan riwayat rujukan dan riwayat dari orangtua. Pemeriksaan yang dilakukan, berupa pemeriksaan fisik dan pemeriksaan ultrasonografi, terapi hormon dan/ atau tindakan operasi yang telah diberikan.

Pasien UDT dikelompokkan berdasarkan asal rujukan yang berumur kurang dari dua tahun atau lebih dari dua tahun. Kriteria diagnosis UDT ditegakkan saat dating ke RSAB Harapan Kita. Selain itu, ditentukan distribusi berdasarkan letak
UDT (unilateral dan bilateral), terapi yang dilakukan (hormonal dan pembedahan), dan keberhasilan terapi hormonal. Kriteria eksklusi adalah DSD, testis retraktil, hipospadia, sindrom tertentu atau multiple anomaly.

Terapi hormonal yang diberikan apabila pasien telah berusia 6 bulan, dan pada pemeriksaan ultrasonografi tampak testis terdapat dalam saluran inguinal. Terapi hormon diberikan hCG sepuluh kali, dua kali seminggu. Terapi tersebut dapat diulang sepuluh kali lagi apabila testis belum turun. Terapi hormon gagal apabila testis tidak turun pada UDT unilateral, turun satu atau tidak turun sama sekali pada UDT bilateral.

\section{Hasil}

Dari 96 pasien yang berobat, 78 pasien di antaranya memenuhi kriteria inklusi penelitian. Pasien merupakan rujukan dari spesialis anak (SpA) non-endokrinologi, spesialis bedah luar RSAB Harapan Kita, dokter umum (DU), maupun datang sendiri (tanpa rujukan). Didapatkan 33 pasien (42\%) datang tanpa rujukan, sedangkan 32 pasien (41\%) dirujuk oleh spesialis anak.

Duapuluh delapan pasien $(35,9 \%)$ terlambat didiagnosis, UDT diketahui setelah berusia lebih dari dua tahun, 23 pasien di antaranya datang tanpa rujukan (Tabel 1).

Dua pasien rujukan dari dokter bedah dirujuk ke Poliklinik Endokrinologi Anak RSAB Harapan Kita karena masih berusia $<6$ bulan, untuk dilakukan terapi hormon terlebih dahulu.

Dari 33 pasien tanpa rujukan, 12 pasien $(36,3 \%)$ orangtua tidak diberitahu tahu bila testis harus turun saat lahir, sedangkan 5 pasien $(15,3 \%)$ orangtua diberitahu tetapi tidak dimengerti. Terdapat 5 pasien dikirim oleh dokter umum dan dokter anak memang

Tabel 1. Distribusi asal rujukan $(n=78)$

\begin{tabular}{lcccc}
\hline \multirow{2}{*}{ Asal rujukan } & \multicolumn{4}{c}{ Usia (tahun) } \\
\cline { 2 - 5 } & $<2$ & 2 & Total & $\%$ \\
\hline Spesialis anak & 30 & 2 & 32 & 41,0 \\
Spesialis bedah & 2 & - & 2 & 39,0 \\
Dokter umum & 8 & 3 & 11 & 14,0 \\
Tanpa rujukan & 10 & 23 & 33 & 42,0 \\
Total & $50(64,1 \%)$ & $28(35,9 \%)$ & $78(100,0 \%)$ & 100,0 \\
\hline
\end{tabular}


sudah tahu saat lahir (Tabel 2). Terdapat 17 pasien $(21,8 \%)$ mengalami UDT bilateral, unilateral kanan 42,3\% dan unilateral kiri 35,9\%. (Tabel 3).

Terapi yang dilakukan pada pasien berupa terapi hormonal dan pembedahan (orchidopexy). Terapi hormon dilakukan pada 48 pasien $(61,5 \%)$ dengan kriteria, yaitu usia 6 bulan-2 tahun dan bersedia diberikan terapi hormon, atau pasien berusia $>2$ tahun, tetapi meminta terapi hormon. Dijumpai 24 pasien $(50,0 \%)$ berhasil dengan terapi hormon. Persentase keberhasilan terapi hormon dilakukan apabila pasien berusia kurang dari satu tahun $(55,6 \%)$, menurun pada usia $1-2$ tahun $(47,6 \%)$ dan usia $>2$ tahun $(33,3 \%)$.

Tiga pasien tidak melakukan terapi hormon sampai selesai dan dianggap gagal dalam terapi.

Tabel 2. Distribusi pasien UDT, tanpa rujukan $(\mathrm{n}=33)$

\begin{tabular}{lcc}
\hline Alasan & Jumlah & $\%$ \\
\hline Tahu, tidak mengerti & 5 & 15,2 \\
Tahu, akan turun sendiri & 10 & 30,3 \\
Tahu, tidak ada biaya & 6 & 18,2 \\
Tidak tahu saat lahir & 12 & 36,3 \\
Total & 33 & 100,0 \\
\hline
\end{tabular}

Tabel 3. Letak UDT ( $\mathrm{n}=78)$

\begin{tabular}{lll}
\hline Letak UDT & Jumlah & $\%$ \\
\hline Unilateral kanan & 33 & 42,3 \\
Unilateral kiri & 28 & 35,9 \\
Bilateral & 17 & 21,8 \\
\hline Total & 78 & 100,0 \\
\hline
\end{tabular}

Tabel 4. Distribusi pasien yang mendapat terapi hormon

\begin{tabular}{lccc}
\hline \multirow{2}{*}{ Usia } & \multicolumn{3}{c}{ Tingkat keberhasilan } \\
\cline { 2 - 4 } & $(+)$ & $(-)$ & Total \\
\hline 6 bulan- 1 tahun & 11 & 8 & 19 \\
$1-2$ tahun & 10 & 10 & 20 \\
$>2$ tahun & 3 & 6 & 9 \\
\hline Total & 24 & 24 & 48 \\
\hline
\end{tabular}

Tabel 5. Distribusi pasien dengan terapi pembedahan

\begin{tabular}{lcc}
\hline \multirow{2}{*}{ Usia (tahun) } & \multicolumn{2}{c}{ Operasi } \\
\cline { 2 - 3 } & $\begin{array}{c}\text { Tanpa } \\
\text { terapi hormon }\end{array}$ & $\begin{array}{c}\text { Terapi } \\
\text { hormon gagal }\end{array}$ \\
\hline$<2$ & 2 & 6 \\
$2-5$ & 8 & 8 \\
$>5$ & 10 & - \\
\hline Total & 20 & 14 \\
\hline
\end{tabular}

Terapi pembedahan (orchidopexy) dilakukan pada 34 pasien, $20(58,8 \%)$ di antaranya langsung dilakukan operasi (karena sudah berusia 2 tahun atau usia kurang dari dua tahun tetapi tidak mau diterapi hormon) dan 14 pasien pembedahan dilakukan setelah gagal terapi hormon. Enambelas pasien $(47,1 \%)$ dilakukan pembedahan pada usia 2-5 tahun, dan berumur lebih dari lima tahun 10 pasien $(29,4 \%)$.

\section{Pembahasan}

Pemeriksaan testis oleh tenaga kesehatan masih belum menjadi prosedur rutin pemeriksaan bayi baru lahir. Padahal pemeriksaan yang benar saat lahir perlu dilakukan oleh setiap tenaga kesehatan atau saat kunjungan pemeriksaan rutin, untuk mendeteksi kasus UDT secara dini.

Pemeriksaan keberadaan testis di dalam skrotum perlu ditentukan pada saat lahir/sedini mungkin. Pemeriksaan dilakukan, apakah masih berada di dalam abdomen (intra-abdominal), inguinal, pre skrotal, intraskrotal, ataukah retraktil. ${ }^{1,6}$ Pemeriksaan ini penting agar tidak terdapat kesalahan saat pemeriksaan.

Sebagian besar rujukan (41\%) berasal dari dokter spesialis anak. Namun angka tertinggi adalah pasien datang sendiri (42\%), dengan berbagai alasan. Disayangkan edukasi terhadap orangtua kurang, terlihat dari data bahwa 12 pasien tidak diberitahu bila testis harus ada di skrotum, 10 pasien sudah tahu saat bayi namun disebutkan akan turun sendiri tanpa diberi penjelasan lebih lanjut, 5 pasien diberitahu, tetapi tidak diberi penjelasan yang jelas, sehingga pasien tidak mengerti. Oleh karena itu, perlu perhatian khusus bagi tenaga kesehatan agar lebih teliti dalam memeriksa dan memberi penjelasan yang jelas.

Sangat memprihatinkan bahwa 35,9\% kasus UDT didiagnosis pada usia lebih dari dua tahun. Sebagaimana diketahui bahwa setelah usia 2 tahun, seperlima bagian sel germinal testis telah mengalami kerusakan, ${ }^{8}$ dapat meningkatkan risiko infertilitas, dan tumor sel germinal. ${ }^{7}$ Penelitian di Bulgaria mendapatkan data yang lebih baik, 3,2\% ditemukan pada usia di bawah satu tahun dan 2,1\% pada usia 1-10 tahun. ${ }^{10}$ Terapi UDT sebaiknya dilakukan pada usia antara enam bulan sampai dua tahun, baik dengan terapi hormonal maupun orchidopexy. ${ }^{6}$

Berdasarkan letak UDT, hasil penelitian kami hampir sama dengan penelitian di Bulgaria dan 
Amerika Serikat. Sebagian besar adalah UDT unilateral kanan, diikuti UDT unilateral kiri dan UDT bilateral dengan persentase makin kecil. ${ }^{10,11,12}$ Karena proses turunnya testis diperantarai oleh hormon, maka pasien UDT dapat diberikan terapi hormon. Hormon hCG digunakan untuk menstimulasi testis agar memproduksi testosteron yang dapat membantu pasien mencapai kadar lokal yang tinggi. ${ }^{6}$

Angka keberhasilan terapi hormon pada penelitian kami 50\%, di India 10\%-50\%, serta 57\%-66\% di Turki. ${ }^{9,13}$

Dari 34 pasien yang dioperasi 10 di antaranya dilakukan operasi di atas umur 5 tahun sehingga sangat mungkin fungsi testis sudah menurun. Penelitian Virtanen (2007) pada kasus UDT bilateral yang menjalani operasi, apabila operasi dilakukan antara usia 10 bulan- 4 tahun $76 \%$ memiliki jumlah sperma normal dan pada usia 4-14 tahun hanya terdapat 26\% kasus. ${ }^{14}$

Penelitian ini menunjukkan bahwa masih banyak kasus UDT terlambat didiagnosis, menyebabkan terapi terlambat diberikan. Keterlambatan mengakibatkan angka keberhasilan terapi hormon makin rendah, dan hasil operasi untuk mendapatkan jumlah sperma normal juga rendah. Dari data yang kami sajikan, perlu dianjurkan pemeriksaan lebih teliti oleh tenaga medis saat bayi lahir maupun saat pemeriksaan lain, sehingga dapat segera diketahui adanya UDT dan menjaga fungsi testis tetap optimal di kemudian hari.

\section{Daftar pustaka}

1. Jack, S, Elder. Disorder and anomalies of the scrotal contents. Dalam Kliegman, Behrman, Jenson, Stanton, penyunting. Nelson Textbook of Pediatrics. Edisi ke-18. Philadelphia: Saunders; 2007. h.545-6.
2. Huston, John M. Orchidopexy. Dalam: Puri P, Holwarth M, Editors. Pediatric Surgery. New York: Springer; 2006.h.555-8.

3. MacKinnon, A.E. The undencended testis. Indian J Pediatr 2005;72: 341-3.

4. Wein, Kavoussi, Novick. The undencended testis. Dalam: Campbell Walls Urology. Edisi ke-9. Philadelphia: Saunders; 2007.

5. Ritze'n EM. Undescended testes: a consensus on management. European J Endocrinol 2008;159:S87-90.

6. Docimo SG, Silver RI, Cromie W. The undescended testicle: diagnosis and management. Am Fam Physic 2000;62:2037-48.

7. Pettersson A, Richiardi L, Nordenskjold A. Age at surgery for undescended testis and risk of testicular cancer. $\mathrm{N}$ Engl J Med 2007;356:237-47.

8. Tanagho EA, Nguyen HT. Embriology of the genitourinary system. Dalam: Tanagho EA, McAninch JW. Smith's General Urology. Edisi 17. California: McGraw Hill companies; 2000. h.23-45.

9. Rohatgi M, Gupta DK, Menon PSN, Subarao P, Verma IC, Rajalakshmy M. Hormonal therapy in undescended testes. Indian J Pediatr 1991; 58:79-83.

10. Kumanov P, Tomova A, Robeva R, Hubaveshki S. Prevalence of cryptorchidism among Bulgarian boys. J Clin Research in Ped Endo 2008;42:72-9.

11. Perez-Brayfield M, Kirsch AJ, Baseman AG. Cryptorchidism. Diunduh dari: www.emedicine.com, pada 26 Januari 2011.

12. Gapanya C, Freya P, Cachat F. Management of cryptorchidism in children: guidelines. Swiss Med Wkly 2008;138:492-8.

13. Aycan Z, Ustünsalih-Inan Y, Cetinkaya E, Vidinlisan S, Ornek A. Evaluation of low-dose hCG treatment for cryptorchidism.Turk J Pediatr 2006;48:228-31.

14. Virtanen HE, Bierknes R, Cortes D. Cryptorchidism: classification, prevalence and long-term consequences. Acta Paediatr 2007; 96:611-6. 